\title{
Innovations
}

\section{Increased Cerebral Cannabinoid-1 Receptor Availability Is a Stable Feature of Functional Dyspepsia: A [ ${ }^{18}$ F]MK-9470 PET Study}

\author{
Huynh Giao Ly ${ }^{a}$ Jenny Ceccarini ${ }^{d}$ Nathalie Weltens ${ }^{a}$ Guy Bormans ${ }^{b}$ \\ Koen Van Laere ${ }^{d}$ Jan Tack ${ }^{a}$ Lukas Van Oudenhove ${ }^{a, c}$ \\ aTranslational Research Center for Gastrointestinal Disorders (TARGID), Department of Clinical and Experimental \\ Medicine, ${ }^{\mathrm{b}}$ Laboratory for Radiopharmacy, Department of Pharmaceutical and Pharmacological Sciences, and \\ ${ }^{c}$ Consultation-Liaison Psychiatry, University Psychiatric Centre KU Leuven, University of Leuven, and ${ }^{\mathrm{d} D i v i s i o n}$ of \\ Nuclear Medicine and Molecular Imaging, University Hospitals Leuven, Leuven, Belgium
}

\section{Key Words}

Endocannabinoids - Cannabinoid-1 receptor .

Functional dyspepsia $\cdot$ Somatic symptom disorders .

Positron emission tomography

\begin{abstract}
Background: Functional dyspepsia (FD) is a prevalent functional gastrointestinal disorder (FGID) defined by chronic epigastric symptoms in the absence of organic abnormalities likely to explain them. Comorbidity with mood and anxiety disorders as well as with other FGIDs and functional somatic syndrome (FSS) is high. FD is characterized by abnormal regional cerebral activity in cognitive/affective pain modulatory circuits, but it is unknown which neurotransmitter systems are involved. The authors aimed to assess and compare in vivo cerebral cannabinoid- $1\left(\mathrm{CB}_{1}\right)$ receptor availability between FD patients and age-, gender- and BMImatched healthy controls (HC). Methods: Twelve FD patients and 12 matched $\mathrm{HC}$ were investigated using positron emission tomography (PET) with the $\mathrm{CB}_{1}$ receptor radioligand $\left[{ }^{18} \mathrm{~F}\right] \mathrm{MK}-9470$. Nine of the patients received a second PET scan after a naturalistic follow-up period of $36 \pm 9.6$ months (range: 25.2-50.4 months). Results: FD patients had significantly higher $\mathrm{CB}_{1}$ receptor availability in the cerebral
\end{abstract}

regions involved in (visceral) nociception (brainstem, insula, anterior cingulate cortex) as well as in the homeostatic and hedonic regulation of food intake [hypothalamus, (ventral) striatum] ( $p<0.05$ corrected for multiple testing, region of interest analysis), which persisted after a follow-up period of $36 \pm 9.6$ months. Conclusions: Although these findings need replication in larger samples, they suggest that the abnormal brain activity in several of these regions, previously demonstrated in FD, may be due to a sustained endocannabinoid system dysfunction, identifying it as a potential novel target for treatment and warranting further studies to elucidate whether it is also a feature of other FGIDs or FSSs.

(c) 2015 S. Karger AG, Basel

\section{Introduction}

Functional dyspepsia (FD) is the most prevalent functional gastrointestinal disorder (FGID) together with the irritable bowel syndrome (IBS). Dyspeptic symptoms affect up to $20 \%$ of the general population, and $70 \%$ of these

Jan Tack and Lukas Van Oudenhove contributed equally to this article as senior authors.

\section{KARGER 125}

(c) 2015 S. Karger AG, Base

0033-3190/15/0843-0149\$39.50/0

E-Mail karger@karger.com

www.karger.com/pps
Lukas Van Oudenhove, $\mathrm{MD}, \mathrm{PhD}$

Herestraat 49, O \& N I, Box 701

BE-3000 Leuven (Belgium)

E-Mail lukas.vanoudenhove@ @ed.kuleuven.be 
symptoms remain 'medically unexplained' [1]. FD is currently defined by the Rome III diagnostic criteria as 'the presence of chronic symptoms thought to originate in the gastroduodenal region in the absence of underlying structural or metabolic disease that could explain the symptoms' [2]. The cardinal dyspeptic symptoms are epigastric pain and burning, postprandial fullness and early satiation, which are often associated with unintentional and unexplained weight loss [3-8]. FD leads to excess diagnostic investigations, significant work absenteeism, impaired health-related quality of life and high prevalence of over-the-counter medication use, all contributing to high health care utilization costs, estimated at USD 18.4 billion in the USA in 2009 [7, 9]. Psychiatric comorbidity in FD, as in other FGIDs, is high, particularly with mood, anxiety and, to a lesser extent, somatization disorder, although the latter may be driven by the restrictive nature of the diagnostic criteria in the Diagnostic and Statistical Manual of Mental Disorders, 4th edition (DSM-IV) [10, 11]. In the general medical literature, FGIDs are considered to be part of the spectrum of functional somatic syndromes (FSS), including fibromyalgia (FM) and chronic fatigue syndrome (CFS), as these syndromes frequently overlap $[12,13]$ and share other features such as high comorbidity with mood and anxiety disorders [14]. More information on how this relates to psychiatric terminology and classification ('somatoform disorders' in DSMIV, 'somatic symptom disorders' in DSM-V) is given in the online supplementary text (for all online suppl. material, see www.karger.com/doi/10.1159/000375454).

Although intensively investigated in the past 2 decades, the pathophysiology of FD remains unclear, and treatment options are limited. FD symptoms have been attributed to complex interactions between peripheral and central mechanisms, including gastric sensorimotor dysfunction, such as delayed gastric emptying, impaired accommodation or visceral hypersensitivity (quantified as lower thresholds to gastric balloon distension), (neuro)immune mechanisms and psychosocial processes, although the exact mechanisms remain unclear $[3,4,11,15-18]$. The 'braingut axis' (BGA) is the complex, bidirectional neurohumoral communication system between the gastrointestinal tract and the brain; it plays a key role in the regulation of appetite and food intake as well as in visceral nociception. Dysfunction of the brain-gut axis has emerged as a generally accepted model to explain the cardinal symptoms of FD in general and the role of central and/or psychological processes in particular $[11,19]$. In an $\mathrm{H}_{2}{ }^{15} \mathrm{O}$ positron emission tomography (PET) study, we found differences in brain activity in regions involved in the processing and modulation of (visceral) pain between FD patients and healthy controls (HC), during rest and (anticipated) painful gastric distension [20]. Our results were confirmed by a recent fluorodeoxyglucose PET study, in which the cerebral glucose metabolism was compared between FD patients and HC during rest. FD patients showed a higher glucose metabolism in regions involved in the processing of visceral homeostatic-afferent information ('homeostatic-afferent' network: thalamus, anterior midcingulate cortex, posterior insula) as well as modulation of these visceral sensory inputs ('emotional-arousal' and 'cortical modulatory' networks: amygdala, pregenual and subgenual anterior cingulate cortex, dorsolateral, ventrolateral and ventromedial prefrontal cortex). Further, differences were found in areas involved in (food) reward processing (the striatum) [21]. These findings are generally in line with findings in other FGIDs/FSSs, including IBS [22], FM [23] and somatoform disorders $[24,25]$, pointing towards a dysfunction of central and descending pain modulatory pathways as a potential common mechanism [23, 26-28]. However, the neurotransmitter system(s) underlying this abnormal resting brain activity in FD remain(s) to be elucidated; this would be a crucial next step to identify potential novel treatment targets.

The endocannabinoid system (ECS) is a neuromodulatory system that includes a family of naturally occurring arachidonate-based lipids, the endocannabinoids [including anandamide ( $\mathrm{N}$-arachidonoylethanolamide) and 2-arachidonoylglycerol], their $\mathrm{G}$ protein-coupled receptors [cannabinoid-1 $\left(\mathrm{CB}_{1}\right)$ and cannabinoid-2 receptors], enzymes involved in endocannabinoid biosynthesis and catabolism, and proteins regulating the uptake and transport of endocannabinoids $[29,30]$. The $\mathrm{CB}_{1}$ receptor is one of the most abundant neuromodulatory receptors in the central nervous system, where it is mainly expressed presynaptically [31]. The ECS plays an important role in the transmission, processing and modulation of pain signals at several levels along the pain pathways, from peripheral sensory nerve endings via the dorsal horn of the spinal cord to (sub)cortical regions of the 'pain neuromatrix' in the brain [32]. More specifically, the ECS is crucially involved in the central and descending pain modulatory system, including the periaqueductal gray (PAG) and the rostral ventromedial medulla $[32,33]$. Further, $\mathrm{CB}_{1}$ receptors are abundant in brain regions involved in the homeostatic and hedonic control of food intake such as the nucleus of the solitary tract, the hypothalamus, amygdala and striatum $[34,35]$. Increased $\mathrm{CB}_{1}$ receptor availability has been found in (sub)cortical brain areas in patients with bulimia and anorexia nervosa using PET 
and the selective ${ }^{18} \mathrm{~F}$-labelled radiotracer $\left[{ }^{18} \mathrm{~F}\right] \mathrm{MK}-9470$ [36]. Based on this body of evidence, most of which comes from animal research, the ECS is a prime candidate neurotransmitter system to explain the differences in regional brain activity between FD patients and HC. However, data on cerebral $\mathrm{CB}_{1}$ receptor availability in FSS/FGID in general and in FD in particular are lacking.

First, we aimed to investigate whether regional cerebral $\mathrm{CB}_{1}$ receptor availability differs between $\mathrm{FD}$ patients and age-, gender- and BMI-matched HC using PET and the $\mathrm{CB}_{1}$ receptor radiotracer $\left[{ }^{18} \mathrm{~F}\right] \mathrm{MK}-9470$ [37]. We hypothesized differences in $\mathrm{CB}_{1}$ receptor availability in key regions involved in the processing and modulation of visceral pain as well as in the homeostatic and hedonic regulation of appetite and food intake. Second, we aimed to determine whether the (altered) $\mathrm{CB}_{1}$ receptor availability in FD patients is a stable feature of the disorder by rescanning patients after a mean follow-up period of 36 months.

\section{Methods and Materials}

\section{Participants}

Twelve FD patients with unintentional weight loss since the onset of symptoms and 12 age-, gender- and BMI-matched HC were included in the study. Patient recruitment took place between August 2008 and December 2010 at the multidisciplinary neurogastroenterology-liaison psychiatry outpatient clinic of the University Hospital Leuven, a tertiary care referral centre. All FD patients were diagnosed based on the Rome III criteria [2]. Prior to inclusion, each patient was screened by means of the MINI-International Neuropsychiatric Interview performed by a trained psychiatrist (L.V.O.) [38]. Exclusion criteria were the presence of comorbid psychiatric disorders (including eating disorders, substance-related disorders and somatization disorder) and/or somatic disorders (including other FSS except IBS), use of psychotropic medications and/or (recreational) drugs. It should be noted, however, that in terms of somatoform disorders, we only excluded somatization disorder as defined by DSM-IV. Thus, the overlap of FD with DSM-IV's 'undifferentiated somatoform disorder' was not explicitly excluded.

The severity of dyspeptic symptoms in FD patients was evaluated using the Dyspepsia Symptom Severity (DSS) scale [39], quantified as the sum of the intensity of 9 dyspeptic symptoms (discomfort, epigastric pain, postprandial fullness, bloating, early satiety, nausea, vomiting, epigastric burning and belching) over the past 3 months, rated on a Likert scale from 0 to 3 [39]. The overall somatic symptom severity ('somatization') was assessed using the $\mathrm{Pa}$ tient Health Questionnaire (PHQ-15) [40], and thoughts, feelings and behaviours related to the somatic symptoms and associated health concerns were assessed using the Illness Attitude Scales (IAS) [41] and the Pain Coping and Cognition List (PCCL) [42].

HC were recruited between March 2005 and July 2007 in response to advertisements on the departmental homepage and in local newspapers and were selected from previous $\mathrm{CB}_{1}$ PET studies $[43,44]$ to obtain a sample that was age-, sex- and BMI-matched

The Endocannabinoid System in

Functional Dyspepsia to the patient sample. All controls were asymptomatic, were screened for neuropsychiatric and other medical disorders and underwent physical examination and blood and urine testing. Inclusion and exclusion criteria were as described previously [43].

Each FD patient received a $\mathrm{CB}_{1}$ PET scan at inclusion (FD1); 9 of the FD patients underwent a second $\mathrm{CB}_{1}$ PET scan (FD2) after a naturalistic (that is, all treatments were allowed) follow-up of 36 \pm 9.6 months (range: 25.2-50.4).

Details about radiotracer characteristics and preparation, imaging procedures (including the acquisition parameters of the standard structural magnetic resonance imaging scan used for the coregistration of the PET images) and image processing are provided in the online supplementary text.

The study was approved by the medical ethics committee of the University Hospitals Leuven (ML7928) and was performed according to the Declaration of Helsinki. After a complete description of the study to the subjects, written informed consent was obtained.

\section{Data Analysis}

Whole-brain voxel-based analysis was conducted using SPM8 (Wellcome Trust Department of Cognitive Neuroscience, London, $\mathrm{UK})$. Absolute $\mathrm{CB}_{1}$ receptor availability differences between FD1 and HC and between FD1 and FD2 were assessed using, respectively, independent-sample and paired Student's tests at a voxel level threshold of $\mathrm{T}>3.4$ (corresponding with $\mathrm{p}_{\text {uncorrected }}$ $<0.001$ ), combined with an extent threshold of $\mathrm{k}_{\mathrm{E}}>100$ voxels. We indicate which clusters survive a more stringent cluster-level threshold of $\mathrm{p}_{\text {FWE-corrected }}<0.05$.

In addition to the whole-brain analysis, a region of interest (ROI) analysis was performed (details in online suppl. text, list in online suppl. table 1). The average modified standard uptake value (mSUV) within each ROI was determined using PMOD and compared by means of independent-sample and paired t tests for FD1 versus $\mathrm{HC}$ and FD1 versus FD2, respectively, using SAS 9.3 (SAS Institute, Cary, N.C., USA). Bootstrapping was used to control the familywise error rate associated with multiple testing [45].

The DSS scores and BMI at FD1 and FD2 were compared by means of paired $t$ tests; individual dyspeptic symptom scores were compared by one-sample $t$ tests with $\mathrm{H}_{0}: \mu_{0}=0$ on the percentage change between FD1 and FD2.

Data are shown as means $\pm \mathrm{SD}$; effect sizes are expressed as Cohen's d.

\section{Results}

\section{Participant Characteristics at Inclusion}

Twelve FD patients (11 women; age: $29.8 \pm 11.0$ years; BMI: $18.4 \pm 2.5)$ as well as 12 gender-, age- and BMImatched HC ( 11 women; age: $25.0 \pm 13.7$ years; BMI: 20.0 \pm 1.3 ) underwent the first scan (FD1). The FD patients scored $13.9 \pm 3.6$ on the DSS and reported a mean weight loss since the onset of the symptoms of $11 \pm 7.4 \mathrm{~kg}$. Mealrelated symptoms (postprandial fullness: mean $\pm \mathrm{SD}=2.1$ \pm 0.3 , range $=2-3$, median $=2$, interquartile range $=2-2$; early satiation: mean $\pm \mathrm{SD}=2.0 \pm 0.5$, range $=1-3$, me- 
Table 1. Regional cerebral $\mathrm{CB}_{1}$ receptor availability in FD patients compared to HC: results of whole-brain, voxel-based statistical parametric mapping analysis

\begin{tabular}{|c|c|c|c|c|c|c|c|c|c|}
\hline \multirow[t]{2}{*}{$\begin{array}{l}\text { Clus- } \\
\text { ter }\end{array}$} & \multicolumn{2}{|l|}{ Cluster level } & \multicolumn{2}{|c|}{ Peak level } & \multicolumn{3}{|c|}{$\begin{array}{l}\text { Local max. MNI } \\
\text { coordinates }\end{array}$} & \multirow[t]{2}{*}{ Anatomical localization } & \multirow[t]{2}{*}{ BA } \\
\hline & p FWE-corrected $k$ & $\mathrm{k}_{\mathrm{E}}$ & $\mathrm{T}$ & puncorrected & $\mathrm{x}$ & $\mathrm{y}$ & $\mathrm{z}$ & & \\
\hline \multirow[t]{2}{*}{1} & \multirow[t]{2}{*}{0.183} & \multirow[t]{2}{*}{431} & 4.11 & 0.000 & 14 & -74 & 30 & Right cuneus & 7 \\
\hline & & & 3.82 & 0.000 & 24 & -64 & 16 & Right posterior cingulate cortex & 31 \\
\hline \multirow[t]{11}{*}{2} & \multirow[t]{11}{*}{0.009} & \multirow[t]{11}{*}{8,307} & 4.07 & 0.000 & -42 & 18 & -18 & Left superior temporal gyrus/inferior frontal gyrus & $38 / 47$ \\
\hline & & & 4.01 & 0.000 & -6 & 0 & 68 & Left supplementary motor area/medial frontal gyrus & 6 \\
\hline & & & 4.01 & 0.000 & -36 & -8 & 60 & Left precentral gyrus & 6 \\
\hline & & & 4.00 & 0.000 & 6 & -8 & 50 & $\begin{array}{l}\text { Right supplementary motor area/anterior midcingulate } \\
\text { cortex }\end{array}$ & $6 / 24$ \\
\hline & & & 3.95 & 0.000 & -30 & 12 & -22 & Left inferior frontal gyrus/ventrolateral prefrontal cortex & 47 \\
\hline & & & 3.85 & 0.000 & -40 & 8 & 0 & Left insula & 13 \\
\hline & & & 3.71 & 0.001 & 14 & 20 & 38 & Right anterior midcingulate cortex & 32 \\
\hline & & & 3.69 & 0.001 & -2 & 4 & -12 & Left subgenual acterior cingulate cortex & 25 \\
\hline & & & 3.62 & 0.001 & 6 & 8 & 30 & Right anterior midcingulate cortex & 24 \\
\hline & & & 3.58 & 0.001 & -14 & 4 & -22 & Left parahippocampal gyrus/uncus & $28 / 34$ \\
\hline & & & 3.55 & 0.001 & -2 & 22 & 28 & $\begin{array}{l}\text { Left perigenual anterior cingulate cortex/anterior } \\
\text { midcingulate cortex }\end{array}$ & 24 \\
\hline \multirow[t]{2}{*}{3} & \multirow[t]{2}{*}{0.164} & \multirow[t]{2}{*}{593} & 4.03 & 0.000 & -52 & 6 & 28 & Left precentral gyrus & 44 \\
\hline & & & 3.60 & 0.001 & -60 & -8 & 30 & Left postcentral gyrus & 43 \\
\hline \multirow[t]{3}{*}{4} & \multirow[t]{3}{*}{0.121} & \multirow[t]{3}{*}{1,128} & 4.03 & 0.000 & -50 & -68 & -16 & Left inferior occipital gyrus & 19 \\
\hline & & & 3.77 & 0.001 & -40 & -80 & -20 & Left fusiform gyrus & 19 \\
\hline & & & 3.54 & 0.001 & -56 & -60 & 16 & Left superior/middle temporal gyrus & $22 / 37$ \\
\hline 9 & 0.151 & 726 & 3.72 & 0.001 & 4 & -66 & -38 & Right cerebellum: vermis & \\
\hline
\end{tabular}

Whole-brain, voxel-based analysis of absolute $\mathrm{CB}_{1}$ receptor availability at a voxel level threshold of $\mathrm{T}>3.4$ (corresponding to $\mathrm{p}_{\text {uncorrected }}<0.001$ ) and an extent threshold of $\mathrm{k}_{\mathrm{E}}>100$ voxels was performed using SPM8. The $\mathrm{CB}_{1}$ receptor availability in FD patients and controls was compared using unpaired Student's t test. Italicized values are significant at an additional cluster level threshold of $\mathrm{p}_{\text {FWE-corrected }}<0.05 . \mathrm{BA}=$ Brodmann area; $\mathrm{FWE}=$ familywise error; $\mathrm{k}_{\mathrm{E}}=$ cluster size extent; $\mathrm{MNI}=$ Montreal Neurological Institute.

dian $=2$, interquartile range $=2-2$ ) were predominant, but epigastric pain was also present in all patients (mean $\pm \mathrm{SD}=1.6 \pm 0.6$, range $=1-3$, median $=2$, interquartile range $=1-2$; online suppl. fig. 1). Therefore, FD patients fulfilled the Rome III criteria for postprandial distress syndrome with overlapping epigastric pain syndrome, 2 subdivisions of FD proposed in the Rome III criteria [2].
Detailed information on somatization (including potential comorbidity with DSM-IV somatoform disorders as well as DSM-V somatic symptom disorders), healthand symptom-related cognitions, feelings and behaviour (obtained using the PHQ-15, the IAS and the PCCL) is provided in the online supplementary text. 
Fig. 1. Regional cerebral $\mathrm{CD}_{1}$ receptor availability in FD patients compared to $\mathrm{HC}$ : results of whole-brain voxel-based analysis. Absolute increase in $\mathrm{CB}_{1}$ receptor availability in FD patients compared to $\mathrm{HC}$ in transverse, coronal and sagittal sections overlaid on a normalized canonical image (ch2better template) available in MRIcro software. The colour bar represents $\mathrm{T}$ scores. aMCC $=$ Anterior midcingulate cortex; $\mathrm{pACC}=$ perigenual anterior cingulate cortex; $s A C C=$ subgenual anterior cingulate cortex.

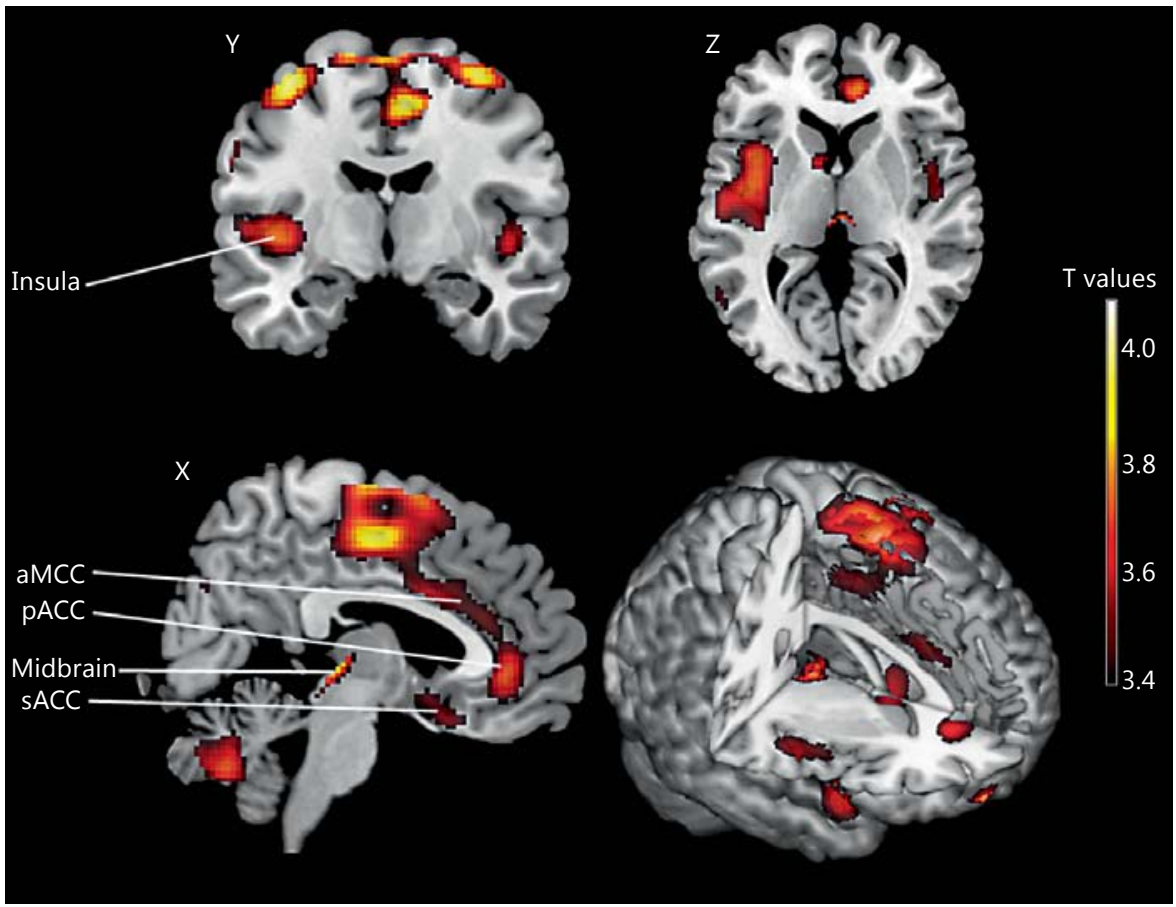

\section{Evolution of DSS and BMI}

Nine of the 12 FD patients ( 8 women; age: $32.9 \pm 12.2$ years) underwent a second scan (FD2) after follow-up. The evolution of the DSS score and the BMI between FD1 and FD2 is summarized in online supplementary figure $2 \mathrm{~A}$ and $\mathrm{B}$, respectively. The observed decrease in the DSS score was borderline significant (FD1: $13.9 \pm 3.6, \mathrm{FD} 2: 10.0 \pm 4.5, \mathrm{p}=$ 0.056 ) with a large effect size (Cohen's $d=0.89$ ), indicating an overall improvement in symptoms. As evident from online supplementary figure $2 \mathrm{~A}$, most patients reported an improvement of their dyspepsia symptoms, with only 2 of the 9 patients $(22.2 \%)$ rating their symptoms as worse. Further, a borderline significant increase in BMI was found (FD1: $18.4 \pm 2.5$, FD2: $20.1 \pm 2 . p=0.058$ ) with a medium effect size (Cohen's $d=0.60$ ), indicating a recovery of weight loss. Seven of the 9 patients $(77.8 \%)$ had gained weight at follow-up.

The results on the evolution of the 9 individual dyspeptic symptoms are shown in the online supplementary text and in online supplementary figure 1.

\section{$C B_{1}$ Receptor Availability in FD versus $H C$}

Whole-brain voxel-based analysis showed a significantly higher absolute $\mathrm{CB}_{1}$ receptor availability in $\mathrm{FD}$ patients compared to $\mathrm{HC}$ with local maxima in the following brain regions: posterior insula, midbrain, ventromedial prefrontal cortex, posterior cingulate cortex, precentral and postcentral gyrus, middle and inferior occipital gyri, superior/middle temporal gyri (including fusiform gyrus), cuneus and cerebellum. One large cluster survived an additional cluster-level threshold of $\mathrm{p}_{\text {FWE-corrected }}<0.05$ with local maxima in the parahippocampal gyrus, rolandic operculum, supplementary motor area, ventromedial prefrontal cortex and ventrolateral prefrontal cortex, precentral gyrus, insula, subgenual and perigenual anterior cingulate cortex and anterior midcingulate cortex. Results are listed in table 1 and visualized in figure 1.

In the FD patient sample, no significant correlation between DSS score and $\mathrm{CB}_{1}$ receptor availability was found in any brain region. However, it should be noted that this correlation analysis has low power given the rather small sample size. Hence, the lack of a significant correlation should be interpreted with great caution.

In keeping with the whole-brain results, the ROI analysis showed a higher regional $\mathrm{CB}_{1}$ receptor availability in FD (range: 19.2-27.7\% compared to HC; online suppl. table 3 and fig. 2A), with all differences being significant after correction for multiple testing, with large effect sizes (all Cohen's d >1.0). As results for the left and right hemisphere were very similar for all ROIs, bilateral ROIs were used. An additional ROI analysis of the PAG and medulla oblongata using SPM8 revealed significant differences in $\mathrm{CB}_{1}$ receptor availability at $\mathrm{p}_{\mathrm{FWE} \text {-corrected }}<0.05$ in the left 


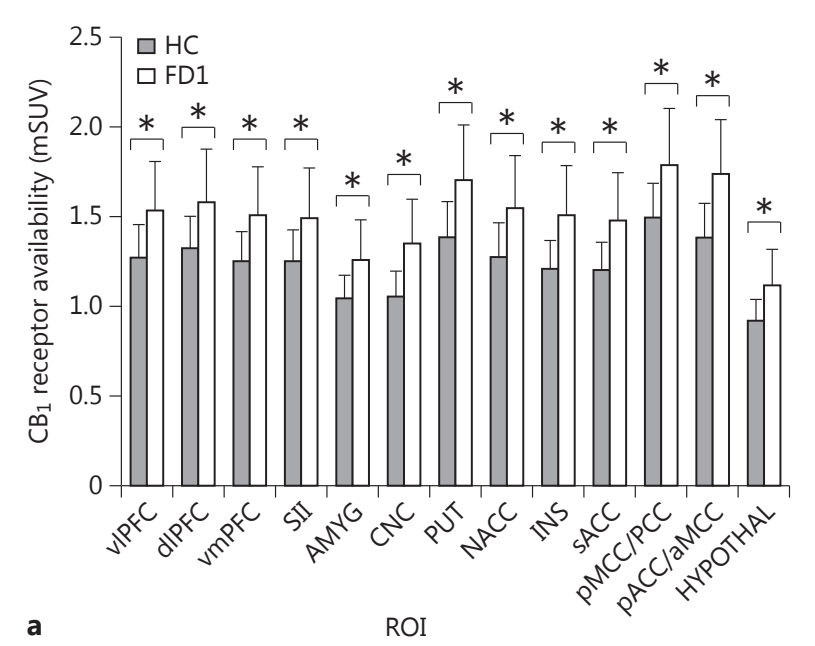

Fig. 2. Regional cerebral $\mathrm{CB}_{1}$ receptor availability: results of ROI analysis. a FD patients (FD1) versus HC. In a priori ROIs, mean mSUVs were calculated and compared using unpaired Student's $t$ test. Bootstrapping was used to correct for multiple testing. $*=$ pbotstrap-corrected $_{\text {b }}<0.05$. b Within the FD patient group: FD1 versus FD2. In a priori ROIs, mean mSUVs were calculated and compared using paired Student's t test. No significant differences were found in any of the ROIs, even without correction for multiple testing. Data represent means $\pm \mathrm{SD}$. vlPFC $=$ Ventrolateral

PAG (local maximum at $\mathrm{x}=-2, \mathrm{y}=-30, \mathrm{z}=-8, \mathrm{~T}=3.75$, $\left.\mathrm{k}_{\mathrm{E}}=100\right)$, but not in the medulla.

\section{Evolution of $\mathrm{CB}_{1}$ Receptor Availability in $\mathrm{FD}$}

Whole-brain voxel-based analysis showed no significant differences in $\mathrm{CB}_{1}$ receptor availability between FD1 and FD2. The results of the ROI analysis confirmed the voxel-based results, as the $\mathrm{CB}_{1}$ receptor availability did not significantly change (all $\mathrm{p}_{\text {uncorrected }}>0.42$ ) in any of the ROIs after an average follow-up of $36 \pm 9.6$ months (online suppl. table 4 and fig. 2B). Effect sizes were small for all ROIs (Cohen's $\mathrm{d}<0.38$ ) (details not shown).

Figure 3 displays the mean global $\mathrm{CB}_{1}$ receptor availability in $\mathrm{HC}$ and FD patients at FD1 and FD2.

\section{Discussion}

We present the first evidence of sustained central ECS dysfunction in FD or indeed in any FGID, FSS or somatoform disorder/somatic symptom disorder. Compared to $\mathrm{HC}, \mathrm{FD}$ patients had higher $\mathrm{CB}_{1}$ receptor availability in regions involved in (visceral) nociception as well as the

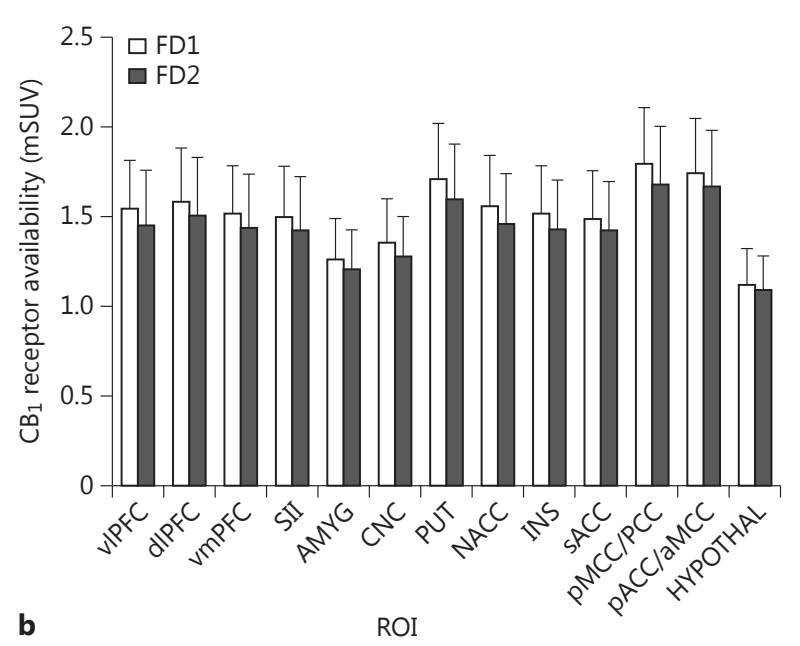

prefrontal cortex; dlPFC $=$ dorsolateral prefrontal cortex; vmPFC = ventromedial prefrontal cortex; SII = secondary somatosensory cortex; $\mathrm{AMYG}=$ amygdala; $\mathrm{CNC}=$ caudate nucleus; PUT = putamen; NACC = nucleus accumbens; INS = insula; $\mathrm{sACC}=$ subgenual anterior cingulate cortex; $\mathrm{pMCC} / \mathrm{PCC}=$ post erior midcingulate cortex/posterior cingulate cortex; $\mathrm{pACC} /$ aMCC $=$ perigenual anterior cingulate cortex/anterior midcingulate cortex; HYPOTHAL = hypothalamus.

homeostatic and hedonic regulation of appetite and food intake, which was stable over a long naturalistic follow-up period of $36 \pm 9.6$ months.

The subjective perception of (visceral) pain is a homeostatic emotion, resulting from coordinated activity in 3 distinct yet highly intertwined cerebral networks: the homeostatic-afferent, emotional-arousal and cortical-modulatory network [19]. The first one is primarily involved in the processing of (visceral) afferent inputs, whereas the other two are primarily pain modulatory networks through which cognition and emotion exert their effects on the perception of (visceral) pain [19,27]. FD is characterized by abnormal neural activity during the anticipation and subsequent processing of painful stimuli in several regions of these networks [20]. More specifically, the altered (de)activation pattern in these patients may represent failure of these pain modulatory systems [20]. We found increased $\mathrm{CB}_{1}$ receptor availability in the homeostatic-afferent (posterior insula, anterior midcingulate cortex), cortical-modulatory (lateral and medial prefronal cortex) and emotional-arousal (amygdala, subgenual anterior cingulate cortex) areas. $\mathrm{CB}_{1}$ receptor availability was also increased in the cerebellum, which has an incompletely understood role in 


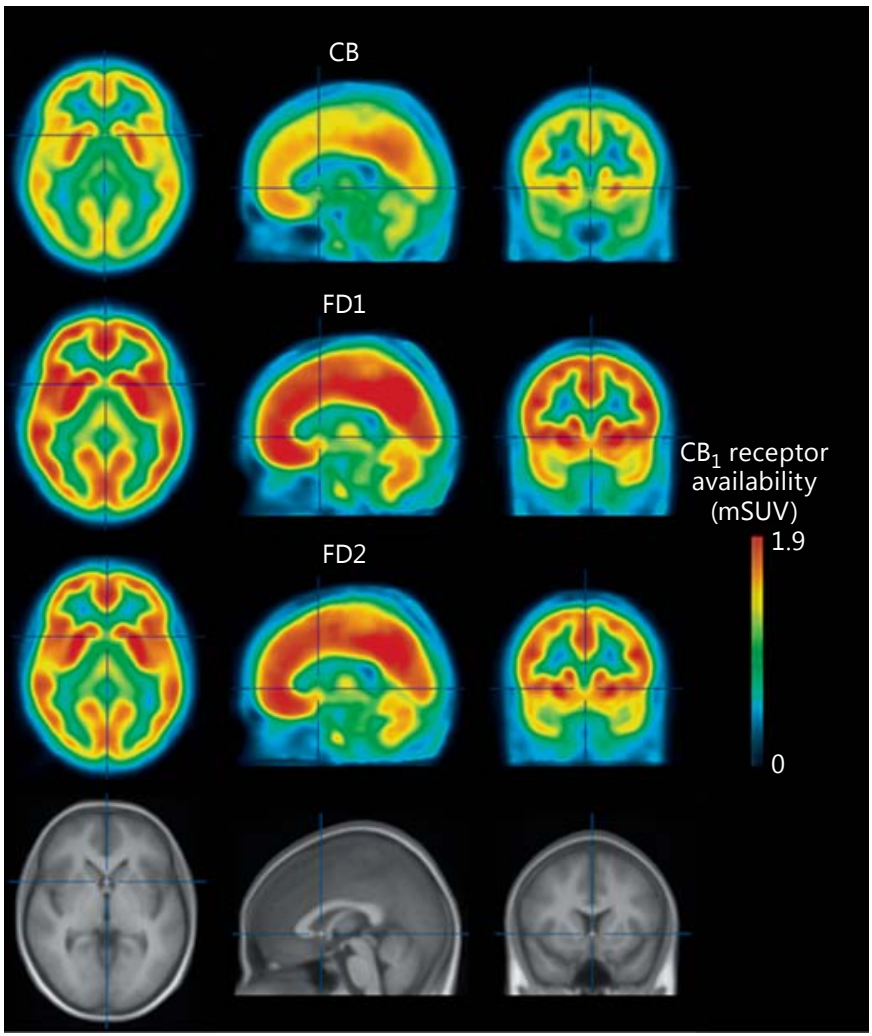

Fig. 3. Parametric images of global $\mathrm{CB}_{1}$ receptor availability in $\mathrm{HC}$ and FD patients at the FD1 and FD2. The colour bar indicates $\mathrm{CB}_{1}$ receptor availability expressed as average $\mathrm{mSUV}$ of the radioligand $\left[{ }^{18} \mathrm{~F}\right] \mathrm{MK}-9470$.

nociception [46], the parahippocampal gyrus and the caudate nucleus, regions associated with cognitive coping strategies during the anticipation of noxious stimuli [47] and anxiety-driven pain modulation [48]. Importantly, the PAG also showed increased $\mathrm{CB}_{1}$ receptor availability. This region is a key hub of the descending pathways originating in central pain modulatory circuits, malfunction of which plays an important role in pathophysiology of FSS, including FGID $[27,28]$. Taken together, these observations advocate for a role of endocannabinoid signalling in altered (visceral) pain processing and its modulation by cognitive and affective factors, thereby contributing to the pathogenesis and/or exacerbation of dyspeptic symptoms like epigastric pain and discomfort. This warrants studies on the involvement of the ECS in other pain-predominant FSS, including IBS and FM, or, more broadly, somatoform disorders or somatic symptom disorders. As this diagnosis is characterized by distressing, often painful symptoms and excessive cognitive-affective processes associated with them, the dysfunction of cognitive-affective pain modula- tory circuitry may be an important mechanism, as shown in somatoform pain disorder patients [24]. Based on our current findings, the ECS may be a candidate neurotransmitter system involved in this dysfunction.

Besides its role in (visceral) nociception, the ECS is also important in regulating feeding behaviour and energy homeostasis, in addition to its role in (visceral) nociception $[32,34,35]$. Activation of the ECS by exogenous cannabinoid agonists increases appetite, especially for sweet and fatty foods [49]. It has been postulated that the orexigenic effects of endocannabinoid signalling in the central nervous system are exerted on 2 functional levels: the hypothalamus (homeostatic) and the reward system (hedonic) [49]. The hypothalamus receives and integrates both central and peripheral input signalling metabolic state. At the level of the reward system, including orbitofrontal cortex, amygdala, ventral striatum (nucleus accumbens) and dorsal striatum (caudate nucleus and putamen), the ECS modulates the motivation to consume food, putatively by increasing both appetite (anticipatory reward) and the hedonic effects of food consumption (consummatory reward) [34]. These orexigenic actions of the ECS are likely mediated by dopamine, as endocannabinoids act as retrograde messengers, exerting their modulatory function in the ventral tegmental area, where dopamine projections to the striatum originate, through modulation of GABAergic and/or glutamatergic synaptic inputs [50]. We found that FD patients show increased $\mathrm{CB}_{1}$ receptor availability in regions involved in both the homeostatic and the hedonic control of appetite and food intake. Thus, we could speculate that dysfunction of the ECS could play a role in the disturbed appetite, weight loss and meal-related symptoms often observed in these patients.

It remains to be elucidated whether elevated $\mathrm{CB}_{1}$ receptor expression in the central nervous system is primarily implicated in abnormal nociception and/or in the disturbed appetite, weight loss and meal-related symptoms, which are also important features of FD. However, the two possibilities are not mutually exclusive as there is mounting evidence for an interaction between pain and reward systems. First, the expectation of pain relief promotes placebo analgesia, and this relief expectancy can be considered as reward expectation [51-53]. Second, several studies in humans and animals have demonstrated a remarkable overlap of brain regions implicated in both pain and reward processing [54]. Last, opioidergic and dopaminergic neurotransmission play an important role in both nociception and reward [55-58]. Taking into account its modulatory effect on both these systems, the dysfunction of the ECS has the potential to alter both pain perception 
and reward processing. Future studies assessing the $\mathrm{CB}_{1}$ receptor availability in patient groups which are characterized by painful physical symptoms only (e.g. IBS and other FSS such as FM), dysregulated appetite and weight only (e.g. obesity) and/or a variable combination of both (e.g. major depression) could clarify whether the ECS changes found in the present study primarily play a role in altered (visceral) nociception and/or dysregulation of appetite and body weight. More specifically, studying $\mathrm{CB}_{1}$ receptor availability in major depression, where loss of appetite and body weight is part of the broader phenomenon of anhedonia, would teach us whether its role is primarily in emotional regulation in general or in appetite regulation in particular. However, using the same $\mathrm{CB}_{1}$ radiotracer $\left[{ }^{18} \mathrm{~F}\right]$ MK-9470, Gérard et al. [36] found significantly elevated $\mathrm{CB}_{1}$ receptor binding in anorexia nervosa patients in comparison with age-matched $\mathrm{HC}$, supporting an involvement of this system in (disorders of) appetite and food intake regulation. Further, the exclusion of comorbid depression in our study sample avoids confounding of the present results in $\mathrm{HC}$ versus FD patients by depressive comorbidity.

In any case, the underlying mechanism for the increased $\mathrm{CB}_{1}$ receptor availability in $\mathrm{FD}$ remains unclear. First, increased $C_{1}$ receptor availability could point to a compensatory receptor upregulation. The authors of the above-mentioned study in eating disorders [36] interpreted the overall increase in $\mathrm{CB}_{1}$ radiotracer binding as an upregulation of $\mathrm{CB}_{1}$ receptors secondary to the previously hypothesized (long-term) hypoactivity of the ECS in these patients [59]. Second, increased $\mathrm{CB}_{1}$ radiotracer binding values in FD could be due to a primary increase in receptor expression, independent from the level of endocannabinoids in the brain [60].

To assess whether the increased cerebral $\mathrm{CB}_{1}$ receptor availability remains stable over time, 9 of the $12 \mathrm{FD}$ patients underwent a second $\mathrm{CB}_{1}$ PET scan after a follow-up period of on average 36 months. No significant differences in $\mathrm{CB}_{1}$ receptor availability between the 2 scan sessions could be found in any of the cerebral regions, despite clear (but borderline significant in this smaller group) improvements in dyspepsia symptoms and weight loss. Thus, the increased $\mathrm{CB}_{1}$ receptor availability in FD seems to be independent of fluctuations in dyspeptic symptom levels or weight loss, suggesting that the elevated $\mathrm{CB}_{1}$ receptor availability found in FD may reflect a primary (predisposing) feature or vulnerability factor, rather than being secondary to symptoms or weight loss. A possible way to further test this hypothesis would be to administer exogenous $\mathrm{CB}_{1}$ receptor antagonists or agonists to $\mathrm{FD}$ patients and subsequently monitor their symptom severity or weight loss, but a lack of suitable ligands currently precludes such study. However, this does not preclude the possibility that the differences found are secondary to disease onset or course (both in terms of dyspeptic symptom burden and/or weight loss). Therefore, further studies in larger samples are needed. Ideally, one should be able to scan the participants prior to and after symptom onset. However, such an approach is not feasible in practice. Therefore, we believe our approach using a follow-up scan is the most preferable and realistic approach.

This study has a number of limitations which should be addressed. First, the strict inclusion criteria, including absence of psychotropic drug use and coexisting mood, anxiety and somatization disorders, resulted in a relatively small sample size. Hence, caution is required in interpreting these results, and replication is needed before any definite conclusions can be drawn. However, the size of our patient sample is comparable to previous $\left[{ }^{18} \mathrm{~F}\right] \mathrm{MK}-9470$ radioligand studies $[36,61]$, and a post hoc power calculation based on the large effect size for all the regions in the ROI analysis (average Cohen's $\mathrm{d}=$ 1.26 ) indicates that the study has $84 \%$ power. Further, the strict inclusion criteria resulted in a relatively homogeneous FD sample carefully matched with $\mathrm{HC}$ for age, gender and BMI, which should be considered a strength. However, a sample of this size does not allow to control for all possible sources of heterogeneity, including variability in gastric sensorimotor function, somatization, etc. Second, as all patients were recruited at a tertiary care centre, our observations do not necessarily apply to the less severely affected FD population. Third, inclusion of a second group of $\mathrm{HC}$ matched for weight loss would have enabled us to evaluate the possible contribution of weight loss to the observed increase in receptor availability in FD. However, it is hardly feasible in practice to recruit $\mathrm{HC}$ with a similar amount of weight loss due to, for instance, dieting, within the lower normal BMI range. Fourth, since the decision to rescan the FD patients was made after the analysis of the PET images of the first scan session, the follow-up period was not standardized in terms of duration and treatment. This explains the considerable range of the follow-up period as well as its naturalistic nature. Fifth, as 3 patients declined participation in the second session, we could only collect a follow-up scan in 9 of the 12 patients.

In summary, this is the first study demonstrating a significant increase in cerebral $\mathrm{CB}_{1}$ receptor availability in FD patients compared to matched $\mathrm{HC}$ in brain regions involved in the regulation of (visceral) pain and the control of food intake. This increase remained stable over a 
long naturalistic follow-up period despite improvement in symptom levels and recovery of weight loss. This study thereby provides the first evidence for an involvement of the central ECS in any FGID or FSS. Given the small sample size, caution is required when interpreting these findings. Additional studies in larger numbers of patients are needed to confirm these results. Further research is warranted to determine whether this elevated receptor availability is primarily implicated in altered gastric nociception, dysregulation of food intake, or both, and to elucidate the mechanisms underlying this increased receptor availability. Moreover, these results warrant further studies on the ECS as a potential novel target for the pharmacological treatment of FD as well as a potentially important candidate mechanism in FGID or FSS in general.

\section{Acknowledgements}

The authors would like to thank all participants as well as Miss Lieselot Holvoet, MSc, for their assistance with patient recruitment and Dr. Michel Koole for his assistance with data preprocessing. Merck Research Laboratories (West Point, Pa., USA) are acknowledged for providing the tracer precursor of $\left[{ }^{18} \mathrm{~F}\right] \mathrm{MK}-9470$, without them involved in the study as a sponsor.
Dr. Ly, Miss Weltens and Professors Tack and Van Oudenhove report grant support from Research Foundation - Flanders (FWOVlaanderen, the Flemish government funding agency) for the submitted work; Prof. Van Oudenhove reports salary support from a fellowship from Research Foundation - Flanders (FWO-Vlaanderen) and a research professorship from the KU Leuven Special Research Fund. Dr. Ceccarini is a postdoctoral fellow of the Research Foundation - Flanders (FWO-Vlaanderen), and Prof. Van Laere is a senior clinical investigator of the Research Foundation - Flanders (FWO-Vlaanderen).

\section{Disclosure Statement}

Dr. Tack reports payment to his institution for scientific advice from Almirall Pharma, AstraZeneca, Cosucra, Danone, GI Dynamics, GlaxoSmithKline, Ironwood, Janssen, Menarini, Novartis, Rhythm, Shire, Takeda, Tsumura, Will Pharma and Zeria, nonfinancial support from Abbott (medication for investigator-initiated study), grants from Alpro, Novartis and Shire, fee for speaker bureau to his institution from Abbott, Almirall, AstraZeneca, Danone, Janssen, Menarini, Novartis, Shire, Takeda and Zeria outside the submitted work, and no other relationships or activities that might have influenced the submitted work. Dr. Ly, Miss Weltens, Dr. Ceccarini, Dr. Bormans, Dr. Van Laere and Dr. Van Oudenhove report no competing interests.

\section{References}

1 Tack J, Talley NJ: Functional dyspepsia symptoms, definitions and validity of the Rome III criteria. Nat Rev Gastroenterol Hepatol 2013;10:134-141.

2 Tack J, Talley NJ, Camilleri M, Holtmann G, Hu P, Malagelada J-R, Stanghellini V: Functional gastroduodenal disorders. Gastroenterology 2006;130:1466-1479.

3 Tack J, Piessevaux H, Coulie B, Caenepeel P, Janssens J: Role of impaired gastric accommodation to a meal in functional dyspepsia. Gastroenterology 1998;115:1346-1352.

4 Tack J, Caenepeel P, Fischler B, Piessevaux H, Janssens J: Symptoms associated with hypersensitivity to gastric distention in functional dyspepsia. Gastroenterology 2001;121:526535.

5 Tack J, Demedts I, Dehondt G, Caenepeel P, Fischler B, Zandecki M, Janssens J: Clinical and pathophysiological characteristics of acute-onset functional dyspepsia. Gastroenterology 2002;122:1738-1747.

6 Tack J, Jones MP, Karamanolis G, Coulie B, Dubois D: Symptom pattern and pathophysiological correlates of weight loss in tertiaryreferred functional dyspepsia. Neurogastroenterol Motil 2010;22:29-35, e4-5.
7 Piessevaux H, De Winter B, Louis E, Muls V, De Looze D, Pelckmans P, Deltenre M, Urbain $\mathrm{D}$, Tack J: Dyspeptic symptoms in the general population: a factor and cluster analysis of symptom groupings. Neurogastroenterol Motil 2009;21:378-388.

8 Jones MP, Talley NJ, Eslick GD, Dubois D, Tack J: Community subgroups in dyspepsia and their association with weight loss. Am J Gastroenterol 2008;103:2051-2060.

9 Lacy BE, Weiser KT, Kennedy AT, Crowell MD, Talley NJ: Functional dyspepsia: the economic impact to patients. Aliment Pharmacol Ther 2013;38:170-177.

10 Dimsdale JE, Creed F, Escobar J, Sharpe M, Wulsin L, Barsky A, Lee S, Irwin MR, Levenson J: Somatic symptom disorder: an important change in DSM. J Psychosom Res 2014; 75:223-228.

11 Van Oudenhove L, Aziz Q: The role of psychosocial factors and psychiatric disorders in functional dyspepsia. Nat Rev Gastroenterol Hepatol 2013;10:158-167.

12 Kanaan RAA, Lepine JP, Wessely SC: The association or otherwise of the functional somatic syndromes. Psychosom Med 2007;69: 855-859.
13 Kim SE, Chang L: Overlap between functional GI disorders and other functional syndromes: what are the underlying mechanisms? Neurogastroenterol Motil 2012;24: 895-913.

14 Henningsen P, Zimmermann T, Sattel H: Medically unexplained physical symptoms, anxiety, and depression: a meta-analytic review. Psychosom Med 2003;65:528-533.

15 Van Oudenhove L, Aziz Q: Recent insights on central processing and psychological processes in functional gastrointestinal disorders. Dig Liver Dis 2009;41:781-787.

16 Vanheel H, Farré R: Changes in gastrointestinal tract function and structure in functional dyspepsia. Nat Rev Gastroenterol Hepatol 2013;10:142-149.

17 Elsenbruch S: Abdominal pain in irritable bowel syndrome: a review of putative psychological, neural and neuro-immune mechanisms. Brain Behav Immun 2011;25:386-394.

18 Kennedy PJ, Clarke G, Quigley EMM, Groeger JA, Dinan TG, Cryan JF: Gut memories: towards a cognitive neurobiology of irritable bowel syndrome. Neurosci Biobehav Rev 2012;36:310-340.

19 Mayer EA, Naliboff BD, Craig AD: Neuroimaging of the brain-gut axis: from basic understanding to treatment of functional GI disorders. Gastroenterology 2006;131:1925-1942.
The Endocannabinoid System in

Functional Dyspepsia
Psychother Psychosom 2015;84:149-158 DOI: $10.1159 / 000375454$ 
20 Van Oudenhove L, Vandenberghe J, Dupont P, Geeraerts B, Vos R, Dirix S, Bormans G, Vanderghinste D, Van Laere K, Demyttenaere K, Fischler B, Tack J: Abnormal regional brain activity during rest and (anticipated) gastric distension in functional dyspepsia and the role of anxiety: a $\mathrm{H}(2)(15) \mathrm{O}-\mathrm{PET}$ study. Am J Gastroenterol 2010;105:913-924.

21 Zeng F, Qin W, Liang F, Liu J, Tang Y, Liu X, Yuan K, Yu S, Song W, Liu M, Lan L, Gao X, Liu Y, Tian J: Abnormal resting brain activity in patients with functional dyspepsia is related to symptom severity. Gastroenterology 2011;141:499-506.

22 Tillisch K, Mayer EA, Labus JS: Quantitative meta-analysis identifies brain regions activated during rectal distension in irritable bowel syndrome. Gastroenterology 2011;140:91100.

23 Gracely R, Ambrose K: Neuroimaging of fibromyalgia. Best Pract Res Clin Rheumatol 2011;25:271-284

24 Gündel H, Valet M, Sorg C, Huber D, Zimmer C, Sprenger T, Tölle TR: Altered cerebral response to noxious heat stimulation in patients with somatoform pain disorder. Pain 2008; 137:413-421.

25 Valet M, Gundel H, Sprenger T, Sorg C, Muhlau M, Zimmer C, Henningsen P, Tolle TR: Patients with pain disorder show graymatter loss in pain-processing structures: a voxel-based morphometric study. Psychosom Med 2009;71:49-56.

26 Mayer EA, Bushnell MC: Functional pain disorders: time for a paradigm shift?; in Mayer EA, Bushnell MC (eds): Functional Pain Syndromes: Presentation and Pathophysiology. Seattle, IASP Press, 2009, pp 531-565.

27 Mayer EA, Tillisch K: The brain-gut axis in abdominal pain syndromes. Annu Rev Med 2011;62:381-396.

28 Farmer AD, Aziz Q: Visceral pain hypersensitivity in functional gastrointestinal disorders. Br Med Bull 2009;91:123-136.

29 Wilson RI, Nicoll RA: Endocannabinoid signaling in the brain. Science 2002;296:678682.

30 Katona I, Freund TF: Endocannabinoid signaling as a synaptic circuit breaker in neurological disease. Nat Med 2008;14:923-930.

31 Matsuda LA, Lolait SJ, Brownstein MJ, Young AC, Bonner TI: Structure of a cannabinoid receptor and functional expression of the cloned cDNA. Nature 1990;346:561-564.

32 Guindon J, Hohmann AG: The endocannabinoid system and pain. CNS Neurol Disord Drug Targets 2009;8:403-421.

33 Wilson-Poe AR, Morgan MM, Aicher SA, Hegarty DM: Distribution of $\mathrm{CB}_{1}$ cannabinoid receptors and their relationship with mu-opioid receptors in the rat periaqueductal gray. Neuroscience 2012;213:191-200.

34 Di Marzo V, Ligresti A, Cristino L: The endocannabinoid system as a link between homoeostatic and hedonic pathways involved in energy balance regulation. Int J Obes 2009; 33(suppl 2):S18-S24.
35 Bermudez-Silva FJ, Cardinal P, Cota D: The role of the endocannabinoid system in the neuroendocrine regulation of energy balance. J Psychopharmacol 2012;26:114-124.

36 Gérard N, Pieters G, Goffin K, Bormans G, Van Laere K: Brain type 1 cannabinoid receptor availability in patients with anorexia and bulimia nervosa. Biol Psychiatry 2011;70: 777-784.

37 Burns HD, Van Laere K, Sanabria-Bohórquez S, Hamill TG, Bormans G, Eng WS, Gibson R, Ryan C, Connolly B, Patel S, Krause S, Vanko A, Van Hecken A, Dupont P, De Lepeleire I, Rothenberg P, Stoch SA, Cote J, Hagmann WK, Jewell JP, Lin LS, Liu P, Goulet MT, Gottesdiener K, Wagner JA, de Hoon J, Mortelmans L, Fong TM, Hargreaves RJ: $\left[{ }^{18} \mathrm{~F}\right] \mathrm{MK}-9470$, a positron emission tomography (PET) tracer for in vivo human PET brain imaging of the cannabinoid-1 receptor. Proc Natl Acad Sci USA 2007;104:98009805.

38 Van Vliet IM, de Beurs E: The MINI-International Neuropsychiatric Interview. A brief structured diagnostic psychiatric interview for DSM-IV in ICD-10 psychiatric disorders (in Dutch). Tijdschr Psychiatr 2007;49:393397.

39 Cuomo R, Sarnelli G, Grasso R, Bruzzese D, Pumpo R, Salomone M, Nicolai E, Tack J, Budillon G: Functional dyspepsia symptoms, gastric emptying and satiety provocative test: analysis of relationships. Scand J Gastroenterol 2001;36:1030-1036.

40 Kroenke K, Spitzer RL, Williams JBW: The PHQ-15: validity of a new measure for evaluating the severity of somatic symptoms. Psychosom Med 2002;64:258-266.

41 Sirri L, Grandi S, Fava GA: The Illness Attitude Scales. A clinimetric index for assessing hypochondriacal fears and beliefs. Psychother Psychosom 2008;77:337-350.

42 de Gier M, Vlaeyen JWS, Van Breukelen G, Stomp SGM, ter Kuile M, Kole-Snijders AMJ, Spinhoven P: Pijn coping en cognitie lijst. Validering en normgegevens. Maastricht, Pijnkenniscentrum Maastricht, 2004.

43 Van Laere K, Goffin K, Casteels C, Dupont P, Mortelmans L, de Hoon J, Bormans G: Gender-dependent increases with healthy aging of the human cerebral cannabinoid-type 1 receptor binding using $\left[{ }^{18} \mathrm{~F}\right] \mathrm{MK}-9470$ PET. Neuroimage 2008;39:1533-1541.

44 Sanabria-Bohórquez SM, Hamill TG, Goffin K, De Lepeleire I, Bormans G, Burns HD, Van Laere K: Kinetic analysis of the cannabinoid-1 receptor PET tracer $\left[{ }^{18} \mathrm{~F}\right] \mathrm{ML}-9470$ in human brain. Eur J Nucl Med Mol Imaging 2010;37: 920-933.

45 Westfall PJ, Young SS: Resampling-Based Multiple Testing. New York, Wiley, 1993.

46 Van Oudenhove L, Coen SJ, Aziz Q: Functional brain imaging of gastrointestinal sensation in health and disease. World J Gastroenterol 2007;13:3438-3445.

47 Kano M, Farmer AD, Aziz Q, Giampietro VP, Brammer MJ, Williams SC, Fukudo S, Coen
SJ: Sex differences in brain response to anticipated and experienced visceral pain in healthy subjects. Am J Physiol Gastrointest Liver Physiol 2013;304:G687-G699.

48 Ploghaus A, Narain C, Beckmann CF, Clare S, Bantick S, Wise R, Matthews PM, Rawlins JN, Tracey I: Exacerbation of pain by anxiety is associated with activity in a hippocampal network. J Neurosci 2001;21:9896-9903.

49 Engeli S: Central and peripheral cannabinoid receptors as therapeutic targets in the control of food intake and body weight. Handb Exp Pharmacol 2012;209:357-381.

50 Maldonado R, Valverde O, Berrendero F: Involvement of the endocannabinoid system in drug addiction. Trends Neurosci 2006;29: 225-232.

51 Petrovic $\mathrm{P}$, Dietrich T, Fransson P, Andersson J, Carlsson K, Ingvar M: Placebo in emotional processing - induced expectations of anxiety relief activate a generalized modulatory network. Neuron 2005;46:957-969.

52 De la Fuente-Fernández R, Ruth TJ, Sossi V, Schulzer M, Calne DB, Stoessl AJ: Expectation and dopamine release: mechanism of the placebo effect in Parkinson's disease. Science 2001;293:1164-1166.

53 Scott DJ, Stohler CS, Egnatuk CM, Wang H, Koeppe RA, Zubieta JK: Individual differences in reward responding explain placebo-induced expectations and effects. Neuron 2007; 55:325-336.

54 Leknes S, Tracey I: A common neurobiology for pain and pleasure. Nat Rev Neurosci 2008; 9:314-320.

55 Petrovic P, Pleger B, Seymour B, Klöppel S, De Martino B, Critchley H, Dolan RJ: Blocking central opiate function modulates hedonic impact and anterior cingulate response to rewards and losses. J Neurosci 2008;28: 10509-10516.

56 Zubieta JK, Smith YR, Bueller JA, Xu Y, Kilbourn MR, Jewett DM, Meyer CR, Koeppe RA, Stohler CS: Regional mu opioid receptor regulation of sensory and affective dimensions of pain. Science 2001;293:311-315.

57 Potvin S, Grignon S, Marchand S: Human evidence of a supra-spinal modulating role of dopamine on pain perception. Synapse 2009; 63:390-402.

58 Volkow ND, Wang GJ, Baler RD: Reward, dopamine and the control of food intake: implications for obesity. Trends Cogn Sci 2011;15: $37-46$.

59 Di Marzo V: Targeting the endocannabinoid system: to enhance or reduce? Nat Rev Drug Discov 2008;7:438-455.

60 Hill MN, Patel S, Carrier EJ, Rademacher DJ, Ormerod BK, Hillard CJ, Gorzalka BB: Downregulation of endocannabinoid signaling in the hippocampus following chronic unpredictable stress. Neuropsychopharmacology 2005;30:508-515.

61 Goffin K, Van Paesschen W, Van Laere K: In vivo activation of endocannabinoid system in temporal lobe epilepsy with hippocampal sclerosis. Brain 2011;134:1033-1040. 